\title{
Necrosis and Inflammation
}

National Cancer Institute

\section{Source}

National Cancer Institute. Necrosis and Inflammation. NCI Thesaurus. Code C139159.

A morphologic finding indicating the presence of necrosis associated with an

inflammatory infiltrate in a tissue sample. 